\title{
PATTERNS OF CHANGE DURING THE DERMOSCOPIC FOLLOW-UP OF MELANOCYTIC LESIONS IN HIGH RISK PATIENTS
}

\author{
LOREDANA UNGUREANU, ALINA LETCĂ, SIMONA CORINA ȘENILĂ, \\ ANA SORINA DĂNESCU, RODICA COSGAREA
}

\author{
Department of Dermatology, Iuliu Haţieganu University of Medicine and \\ Pharmacy, Cluj-Napoca, Romania
}

\begin{abstract}
Background. Melanomas and melanocytic nevi that change over time display different change patterns, correlated with histopathological features.

Methods. We performed a retrospective analysis of the dermoscopic images corresponding to 86 lesions excised due to the changes occurred during the follow-up period in patients at high risk for melanoma, and we drew a comparison between the changes occurring in melanomas and those occurring in melanocytic nevi.

Results. There were significant differences between the models of dermoscopic change characteristic to melanoma and those characteristic to melanocytic nevi. We observed changes with high specificity for the diagnosis of melanoma - asymmetric growth $(S p=90 \%)$, new structureless grey-blue areas (Sp=97.5\%) or new grey-blue network $(S p=96.25 \%)$, new pseudopods or radial streaks $(S p=95 \%)$.

Conclusion. Our study highlights highly specific changes whose presence should raise the suspicion of melanoma and lead to the excision of the lesion.
\end{abstract}

Keywords: dermoscopy, melanoma, melanocytic nevi.

\section{Introduction}

Melanoma is an aggressive, treatment-resistant tumour of the melanocytes, which has the fastest growing incidence worldwide [1]. The current spectrum of this tumour includes two extremes. At one end, there are the thin primary cutaneous melanomas characterized by standard treatment and a good prognosis in case of adequate surgical treatment. At the opposite end, there is the metastatic melanoma for which there is no proven treatment and which associates with adverse prognosis. Given that the treatment for advanced melanoma has only limited impact on the overall survival and prognosis, although new therapeutic agents are now available, researchers make significant efforts to understand the pathology, genetics and immunology of melanoma and especially to find reproducible methods for its early diagnosis [2].

Acquired melanocytic nevi $(\mathrm{MN})$ are independent

Manuscript received: 05.01.2015

Accepted: 12.01.2015

Address for correspondence: danaszent@yahoo.com risk factors for cutaneous melanoma, and the total number of melanocytic nevi is the most important independent risk factor for melanoma, as the risk for melanoma increases linearly with the number of melanocytic nevi [3]. The presence of dysplastic melanocytic nevi (DMN) is an additional independent risk factor for melanoma [4]. However, the exact etiologic role of $\mathrm{MN}$ in the development of melanoma has not been established. It has been suggested that common melanocytic nevi (CMN), DMN and melanoma (M) represent distinct evolutionary stages of melanocytic lesions; however, there is no evidence to suggest a mandatory progression through these stages [2]. Moreover, it has been proven that melanoma occurs most often de novo, rarely developing on pre-existing lesions, be they CMN or DMN [2]. Unfortunately, there is no possibility to predict which common or atypical nevus will progress to melanoma. Excision of all lesions is impossible in patients with multiple nevi and would associate with significant disfigurement, morbidity and increased costs. Starting from the assumption that benign lesions are stable, while 
malignant lesions tend to change, the follow-up of patients at increased risk for melanoma at regular intervals has been proposed as a strategy to recognize early-stage cutaneous melanoma [5]. The methods proposed for monitoring atypical nevi and detecting new pigmented tumour were: periodical self-examination (useless in the absence of dramatic changes), photography of the entire body surface (detection of early small melanomas is difficult using this method) and dermoscopy [5].

The aim of this retrospective study was to assess the dermoscopic changes occurring during follow-up of melanocytic lesions in patients at high risk for melanoma, in order to identify the changes that indicate malignancy.

\section{Materials and methods}

\section{Setting and design of the study}

The object of this retrospective study consisted in 86 equivocal pigmented lesions monitored dermoscopically before excision. The lesions were monitored and excised in the Department of Dermatology, Cluj, between January 2006 - December 2012 (72 months) and represented 2.9\% of all 2965 lesions monitored in 1406 patients.

The lesions were excised because their dermoscopic appearance changed during follow-up, and these changes were considered to be significant by two independent evaluators (LU, RC). The significant dermoscopic changes were defined as asymmetric increase in size, asymmetric pigmentation change or new structures suggestive for melanoma.

On the first examination all lesions looked dermoscopically atypical, but did not meet the criteria for melanoma, using the dermoscopic pattern analysis. The follow-up visits were scheduled at different intervals, ranging between 3 to 12 months, depending on the dermoscopical atypia. The 3-month follow-up was used for lesions with moderate degree of atypia and the 6-12 month follow-up for those with low degree of atypia. The lesions were dermoscopically recorded on the first examination and on the subsequent visits using a Heine Delta 20 dermoscope. The dermoscopic images were stored in the MoleMax Photo follow-up programme.

The study did not include lesions located at genital level, palmar-plantar level or at the cephalic extremity, due to the specificity of their dermoscopic pattern. History of trauma and recent exposure (over the past three months) to natural or artificial ultraviolet radiation were further exclusion criteria.

After excision the lesions were histopathologically examined and divided into two categories: melanocytic nevi and melanomas. In their turn, melanocytic nevi were divided into dysplastic melanocytic nevi (DMN) and common melanocytic nevi (CMN).

Dermoscopic changes evaluated in the study:

The dermoscopic images recorded during the first visit and on the last visit before excision of the lesion were compared in order to detect any dermoscopic changes, using the following variables:

1. Change of size

2. Change of pigmentation/colour:

- Accentuation of the pigmentation or colour

- Depigmentation - including new light brown areas.

3. New dermoscopic structures:

- Grey-blue structures - structureless grey-blue areas, grey-blue network, grey-blue dots/globules

- White structures

- Red structures

- Brown or black dots/globules

4. Pigment network changes - atypical pigment network, pseudopods/irregular extensions.

These variables were selected from the literature in the field and are considered to be significant [6-10].

The dermoscopic changes that occurred during follow-up in melanocytic nevi were compared with those observed in melanoma to detect the changes that raise suspicion of malignancy.

Statistical evaluation

For the statistical analysis we used the SPSS (Statistical Package for the Social Sciences) software version 20 and the MedCalc software version 12.5.

The data were labelled as nominal or continuous variables. For the nominal variables we calculated frequencies. To test the normality of the distribution of continuous variables we used the Kolmogorov-Smirnov test, and to determine the central tendency we used the \pm mean standard deviation for normally distributed data. Thus, for the analysis of continuous variables with normal distribution, we used the Student $t$ test for independent samples. For the univariate analysis of nominal variables, we used the $\chi^{2}$ test. The statistical significance threshold was set at 0.05 .

\section{Results}

The study included 29 (33.7\%) male patients and 57 $(66.3 \%)$ female patients.

The age range of the patients included in the study was between 13 years and 63 years, with a mean age of $35.2 \pm 12.2$ years.

The subjects were followed for a minimum of 3 months and a maximum of 72 months, with a median of $15.2(8.75,36)$ months.

The histopathological examination revealed 50 (58.1\%) dysplastic melanocytic nevi, 30 (34.9\%) common melanocytic nevi and 7 (6\%) melanomas.

\section{Dermoscopic changes in melanomas versus melanocytic nevi:}

In the first part of the study we compared the changes which occurred in melanomas with those in melanocytic nevi (dysplastic and common nevi). No statistically significant differences were found between the two groups 


\section{Dermatology}

with regard to age and sex of the patients.

Table I shows the frequency of occurrence of the different dermoscopic changes monitored in the two groups. We found statistically significant differences between the two groups regarding the increase in size $(\mathrm{p}=0.01)$, depigmentation $(\mathrm{p}=0.007)$, the appearance of grey-blue structures $(\mathrm{p}=0.007)$ and changes of the pigment network $(\mathrm{p}=0.03)$.

Table II shows the validity of the dermoscopic changes with statistical significance monitored in our study.

Dermoscopic changes in dysplastic melanocytic nevi versus common melanocytic nevi:

In the second part of the study we compared the changes which occurred in dysplastic melanocytic nevi with those in common melanocytic nevi. We found statistically significant differences between the two groups regarding depigmentation $(\mathrm{p}<0.001)$, the appearance of grey-blue structures $(p=0.007)$ and changes of the pigment network $(\mathrm{p}=0.01)$.

Table III shows the validity of the dermoscopic changes with statistical significance in differentiating between the DMN/CMN.

Dermoscopic changes in melanomas versus dysplastic melanocytic nevi:

In the third part of the study we compared the changes which occurred in melanomas with those in

Table I. Analysis of the dermoscopic changes between the first visit and the last visit before excision during follow-up in the melanoma group versus the melanocytic nevi group.

\begin{tabular}{|c|c|c|c|c|}
\hline \multicolumn{2}{|c|}{ Dermoscopic change } & Melanomas & $\begin{array}{l}\text { Melanocytic } \\
\text { nevi }\end{array}$ & $\begin{array}{l}\text { Statistical } \\
\text { analysis }\end{array}$ \\
\hline \multirow{2}{*}{ Increase in size } & symmetric & $0 / 6(0 \%)$ & $8 / 80(10 \%)$ & \multirow{2}{*}{$\begin{array}{c}\text { test } \chi^{2} ; p=0.01 \\
H R=1.8\end{array}$} \\
\hline & asymmetric & $3 / 6(50 \%)$ & $22 / 80(27.5 \%)$ & \\
\hline \multirow{2}{*}{$\begin{array}{l}\text { Accentuation of the } \\
\text { pigmentation }\end{array}$} & Eccentric pigmentation & $1 / 6(16.6 \%)$ & $5 / 80(6.25 \%)$ & \multirow{2}{*}{ test $\chi^{2} ; \mathrm{p}=0.5$} \\
\hline & Symmetrical accentuation & $0 / 6(0 \%)$ & $13 / 80(16.2 \%)$ & \\
\hline Depigmentation & Light-brown areas & $5 / 6(83.3 \%)$ & $29 / 80(36.25 \%)$ & test $\chi^{2} ; p=0.007$ \\
\hline \multirow{3}{*}{$\begin{array}{l}\text { New grey-blue } \\
\text { structures }\end{array}$} & $\begin{array}{c}\text { Structureless grey-blue } \\
\text { areas GBA }\end{array}$ & $2 / 6(33.3)$ & $2 / 80(2.5 \%)$ & \multirow{3}{*}{$\begin{array}{l}\text { test } \chi 2 ; \mathrm{p}=0.007 \\
\mathrm{HR}=11.2(\mathrm{GBA}) \\
\mathrm{HR}=6.7,(\mathrm{GBN})\end{array}$} \\
\hline & Grey-blue network & $1 / 6(16.6 \%)$ & $3 / 80(3.75 \%)$ & \\
\hline & Grey-blue dots / globules & $1 / 6(16.6 \%)$ & $27 / 80(33.75 \%)$ & \\
\hline New white structures & & $0 / 6(0 \%)$ & $3 / 80(3.75 \%)$ & test $\chi 2 ; \mathrm{p}=1$ \\
\hline \multirow{2}{*}{ New red structures } & Polymorphic pattern & $1 / 6(16.6 \%)$ & $3 / 80(3.75 \%)$ & \multirow{2}{*}{ test $\chi^{2} ; p=0.2$} \\
\hline & Red structureless areas & $0 / 6(0 \%)$ & $7 / 80(8.75 \%)$ & \\
\hline \multirow{2}{*}{$\begin{array}{l}\text { Pigment network } \\
\text { changes }\end{array}$} & Atypical pigment network & $1 / 6(16.6 \%)$ & $19 / 80(23.75 \%)$ & \multirow{2}{*}{$\begin{array}{c}\text { test } \chi^{2} ; p=0.03 \\
\mathrm{HR}=5\end{array}$} \\
\hline & $\begin{array}{c}\text { Pseudopods/irregular } \\
\text { extensions }\end{array}$ & $2 / 6(33.3 \%)$ & $4 / 80(5 \%)$ & \\
\hline \multirow{3}{*}{$\begin{array}{l}\text { New brown or } \\
\text { black dots/globules }\end{array}$} & Peripheral & $1 / 6(16.6 \%)$ & $10 / 80(12.5 \%)$ & \multirow{3}{*}{ test $\chi 2 ; p=0.2$} \\
\hline & Central & $3 / 6(50 \%)$ & $14 / 80(17.5 \%)$ & \\
\hline & On the entire surface & $1 / 6(16.6 \%)$ & $28 / 80(35 \%)$ & \\
\hline
\end{tabular}

Table II. The validity of the various dermoscopic changes in differentiating between melanoma/melanocytic nevus.

\begin{tabular}{|l|c|c|c|c|}
\hline Dermoscopic change & $\begin{array}{c}\text { Sensitivity } \\
\%\end{array}$ & $\begin{array}{c}\text { Specificity } \\
\%\end{array}$ & $\begin{array}{c}\text { Positive } \\
\text { predictive } \\
\text { value } \%\end{array}$ & $\begin{array}{c}\text { Negative } \\
\text { predictive } \\
\text { value } \%\end{array}$ \\
\hline Asymmetric growth & 50.00 & 90.00 & 27.27 & 96 \\
\hline New light-brown areas & 83.3 & 63.76 & 14.71 & 98.08 \\
\hline $\begin{array}{l}\text { New structureless } \\
\text { grey-blue areas }\end{array}$ & 33.33 & 97.5 & 50 & 95.12 \\
\hline New grey-blue network & 16.67 & 96.25 & 25 & 93.90 \\
\hline New pseudopods & 33.3 & 95.00 & 33.3 & 95 \\
\hline
\end{tabular}

Table III. The validity of the various dermoscopic changes in differentiating between dysplastic melanocytic nevi / common melanocytic nevi.

\begin{tabular}{|l|c|c|c|c|}
\hline Dermoscopic change & $\begin{array}{c}\text { Sensitivity } \\
\%\end{array}$ & $\begin{array}{c}\text { Specificity } \\
\%\end{array}$ & $\begin{array}{c}\text { Positive } \\
\text { predictive } \\
\text { value } \%\end{array}$ & $\begin{array}{c}\text { Negative } \\
\text { predictive } \\
\text { value } \%\end{array}$ \\
\hline New light-brown areas & 52.2 & 90.00 & 89.66 & 52.94 \\
\hline New grey-blue dots/globules & 46.00 & 86.8 & 85.19 & 49.05 \\
\hline New pseudopods & 8.00 & 100.00 & 100.00 & 39.47 \\
\hline
\end{tabular}


dysplastic melanocytic nevi. We found statistically significant differences between the two groups regarding depigmentation $(p=0.002)$ and the appearance of grey-blue structures $(\mathrm{p}=0.007)$.
Table IV shows the validity of the various dermoscopic changes with statistical significance in differentiating between $\mathrm{M} / \mathrm{DMN}$.

Table IV. The validity of the various dermoscopic changes in differentiating between melanoma/dysplastic melanocytic nevi.

\begin{tabular}{|l|c|c|c|c|}
\hline Dermoscopic change & $\begin{array}{c}\text { Sensitivity } \\
\%\end{array}$ & $\begin{array}{c}\text { Specificity } \\
\%\end{array}$ & $\begin{array}{c}\text { Positive } \\
\text { predictive } \\
\text { value \% }\end{array}$ & $\begin{array}{c}\text { Negative } \\
\text { predictive } \\
\text { value \% }\end{array}$ \\
\hline New light-brown areas & 83.3 & 48 & 16.13 & 96 \\
\hline New grey-blue network & 16.67 & 94 & 25 & 90.38 \\
\hline New grey-blue dots/globules & 46.00 & 83.3 & 95.83 & 15,62 \\
\hline
\end{tabular}
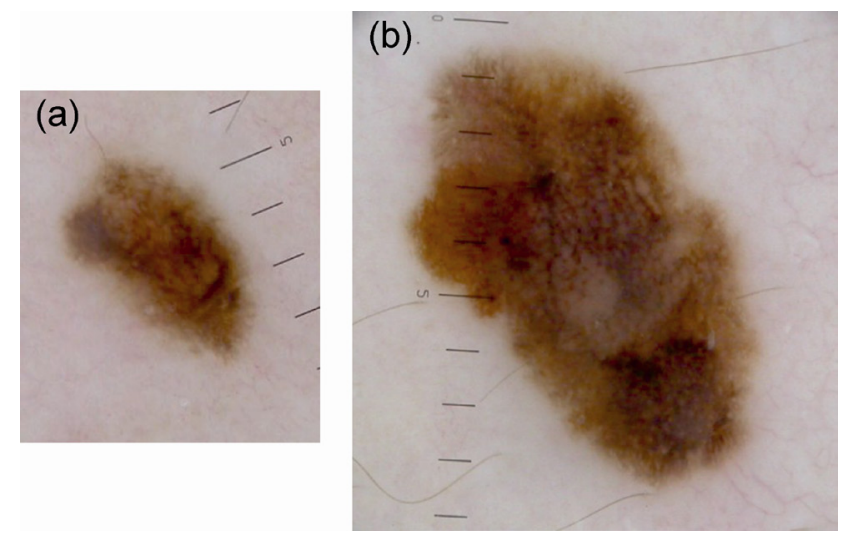

A. In situ melanoma: asymmetric growth, light brown areas, grey-blue network, atypical pigment network (a. first visit, b. last visit before excision, follow-up period - 18 months).
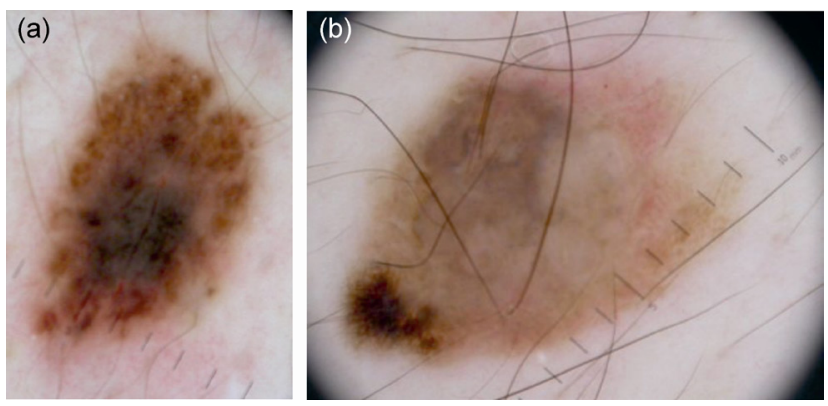

B. Invasive melanoma (IB=1.9 $\mathrm{mm})$ : asymmetric growth, eccentric pigmentation, structureless grey-blue areas, light brown areas, atypical pigment network, irregular extension, polymorphic vascular pattern (a. first visit, b. last visit before excision, followup period - 72 months, the patient discontinued follow-up for 66 months).
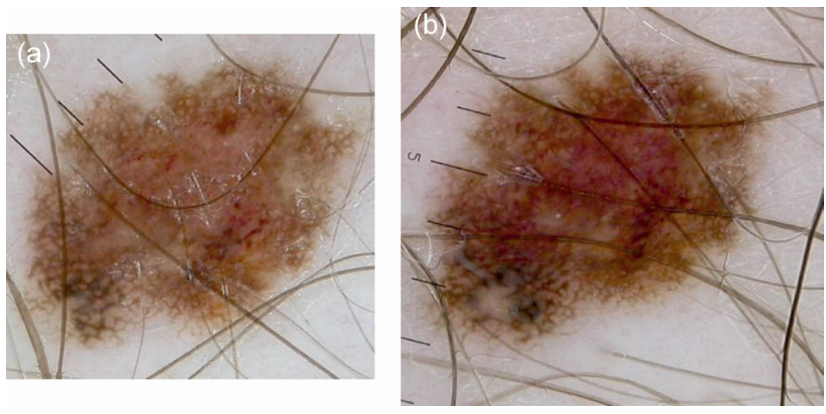

C. Dysplastic melanocytic nevus: asymmetric growth, light brown areas, grey-blue dots/globules, atypical network. (a. first visit, b. last visit before excision, follow-up period - 24 months).
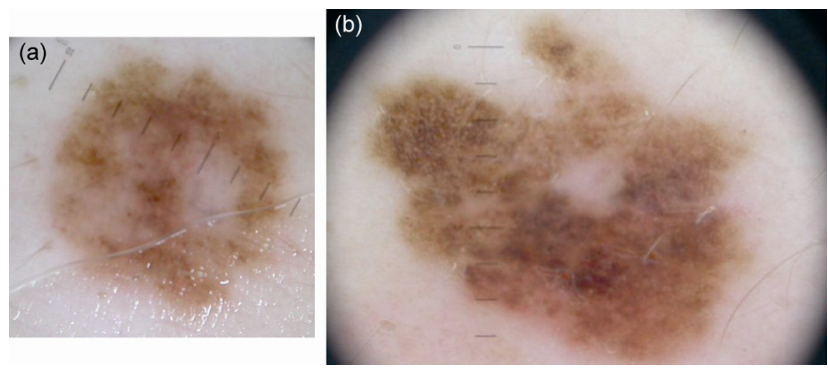

D. Dysplastic melanocytic nevus: asymmetric growth, light brown areas, grey-blue dots/globules, atypical network. (a. first visit, b. last visit before excision, follow-up period - 48 months).
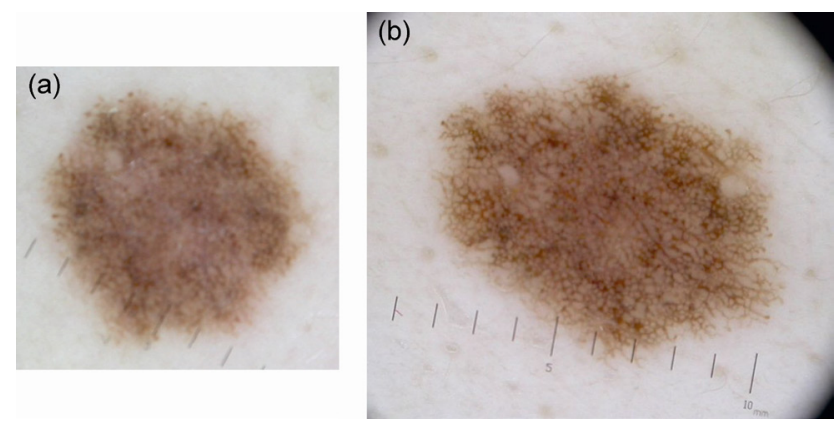

E. Common melanocytic nevus: asymmetric growth, irregular dots/globules (a. first visit, b. last visit before excision, follow-up period -6 months).

Figure 1. Patterns of change in melanoma, dysplastic melanocytic nevi and common melanocytic nevi during follow-up. 


\section{Discussion}

The aim of the present study was to evaluate the results of the dermoscopic follow-up in patients at high risk for melanoma and to identify the dermoscopic changes that occur and characterize benign and malignant melanocytic lesions. The significant changes considered to be an indication for excision in this study were: asymmetric change in size, asymmetric change in colour and appearance of new structures suggestive for melanoma [6-10].

During the dermoscopic follow-up we observed significant changes in 86 melanocytic lesions representing $2.9 \%$ of all the followed-up lesions. This percentage is within the range reported by other dermoscopic follow-up studies (1.3-18.7\%), supporting the idea that the majority of melanocytic lesions are stable over time or display only minor changes that do not require excision [11].

Most of the excised lesions were melanocytic nevi (93\%) with a predominance of the dysplastic melanocytic nevi $(58.1 \%)$, and with only 6 excised melanomas (7\%). These observations suggest that most of the lesions that change in time are benign lesions, not melanomas, and that only when changes are prominent or significant, excision is required. The value of the dermoscopic follow-up resides not only in detecting changes in the nevi, but most importantly in identifying early melanomas [12].

The results of the present study demonstrate that there are statistically significant differences between the patterns of dermoscopic change characteristic of melanoma, dysplastic melanocytic nevi and common melanocytic nevi (Fig. 1).

\section{Change of size}

Most melanocytic lesions that alter substantially do not vary in size. Thus, $62.5 \%$ of the melanocytic nevi and $50 \%$ of the melanomas included in the study showed no increase in size during follow-up. When the lesion grows in size, the change tends to be asymmetric in case of melanomas and symmetric in melanocytic nevi, the differences being statistically significant. Although its sensitivity is not increased, asymmetric growth is specific to melanoma ( $\mathrm{Sp}=90 \%$ ). We observed no statistically significant differences in terms of size variations when comparing dysplastic melanocytic nevi and common melanocytic nevi.

\section{Pigmentation or colour change}

Appearance of eccentric pigmentation has been more frequent in patients with melanoma than in those with melanocytic nevi, and symmetrical accentuation of the pigmentation was only noted in patients with melanocytic nevi, but the differences were not statistically significant.

The development of light brown areas as a way of depigmentation differs significantly between the group of melanomas and that of melanocytic nevi. Thus, the patients in whom light-brown areas appear have a HR of 9 for developing melanoma, in comparison with those in which these structures are not observed. Also, light brown areas appear significantly more often in malignant lesions than in dysplastic melanocytic nevi throughout the follow-up. When comparing the group of melanomas to the group of melanocytic nevi, we noticed that the appearance of light brown areas is highly sensitive for melanoma, but it is not specific to it ( $\mathrm{Se}=83.3 \%, \mathrm{Sp}=63.75 \%$ ); when comparing the group of dysplastic melanocytic nevi and that of common melanocytic nevi we noticed low diagnostic sensitivity, but increased specificity $(\mathrm{Se}=52 \%, \mathrm{Sp}=90 \%)$.

Light brown areas were first described by Annessi et $a l$. as irregular pale brown areas occurring on the periphery of melanocytic lesions and associated with melanoma [13]. Subsequently, this term also included the structureless light brown areas occurring within a structured area due to the fading of the pigmented network, of the globules or of the structureless dark brown areas [9]. These dermoscopic structures may represent the initial stage of the phenomenon of regression, followed in a more advanced stage by the appearance of the grey-blue structures [9].

\section{The grey-blue structures}

This study showed that melanomas, dysplastic melanocytic nevi and common melanocytic nevi develop different grey-blue structures during dermoscopic followup. As they progresses, melanomas are characterized by the appearance of structureless grey-blue areas and of grey-blue network, while in case of dysplastic melanocytic nevi, grey-blue dots/globules are more frequent. According to our study, grey-blue structures are rare in common melanocytic nevi.

Although they do not have high sensitivity for the diagnosis of melanoma, both structureless grey-blue areas and grey-blue network are highly specific for it $(\mathrm{Sp}=97.5 \%$ and $\mathrm{Sp}=96.25 \%$ ). On the other hand, the appearance of grey-blue globules is specific to dysplastic melanocytic nevi, although its diagnostic sensitivity is not high $(\mathrm{Se}=46 \%, \mathrm{Sp}=83.3 \%)$.

New white and red dermoscopic structures were rarely observed in the lesions monitored in this study and were not statistically significant. A possible explanation could be that this kind of structures occur in advanced stages of melanoma progression, and are not specific to early melanomas and nevi.

\section{Changes in the pigment network}

In the present study the development of atypical pigment network and pseudopods was observed in both melanomas and dysplastic melanocytic nevi, but not in common melanocytic nevi. However, pseudopods were significantly more often observed in melanoma, the appearance of these structures being highly specific $(\mathrm{Sp}=95 \%)$ for early malignant lesions, but not sensitive for their diagnosis $(\mathrm{Se}=33.3 \%)$.

It was noted that a frequent dermoscopic pattern of in situ melanomas is the reticular one, and the diagnosis of these lesions is often based on the changes occurring in the pigment network [14]. Seidenari et al. have shown that, in 
practical terms, in case of lesions with pigmented network, the absence/presence of the atypical pigment network is sufficient to confirm/exclude the indication of surgical excision of the lesion. Subsequently, additional analysis is required to differentiate between early melanomas and dysplastic melanocytic nevi based on other dermoscopic criteria, in order to prioritize excision [14].

\section{Brown or black dots/globules}

During the dermoscopic follow-up we did not notice any significant differences in the occurrence of these structures in melanomas, dysplastic melanocytic nevi and common melanocytic nevi. Although the threshold of statistical significance was not reached, we observed that during the dermoscopic follow-up dots/globules occurred especially in the central part of the lesion in the case of melanomas, and especially peripherally in melanocytic nevi.

\section{Conclusions}

Despite the fact that the criterion of "progression" was included in the ABCDE algorithm for the diagnosis of melanoma, there are no objective data to indicate exactly which changes are typical or suggestive of malignancy, particularly in early, small lesions. The present study demonstrates that during dermoscopic follow-up, atypical melanocytic lesions and melanoma evolve differently. Thus, dermoscopic follow-up is particularly useful in patients with multiple melanocytic lesions. The main advantages of this technique are the identification of malignant lesions at an early stage and the reduction of the number of unnecessary excisions.

This study allowed us to observe certain changes whose specificity is very high for the diagnosis of melanoma - asymmetric growth, appearance of structureless greyblue areas or of the grey-blue network, appearance of pseudopods or of radial streaks. Thus, the presence of any of these changes should raise the suspicion of melanoma and lead to the excision of the lesion.

Although this study showed no singular dermoscopic change with very high sensitivity that would allow us to establish the diagnosis of melanoma in all cases, it allowed for the description of highly specific changes that indicate the need for excision.

\section{Acknowledgement}

This paper was published under the frame of European Social Fund, Human Resources Development Operational Programme 2007-2013, project no. POSDRU/159/1.5/S/138776.

\section{References:}

1. Siegel R, Ward E, Brawley O, Jemal A. Cancer statistic 2011: the impact of eliminating socioeconomic and racial disparities on premature cancer deaths. CA Cancer J Clin. 2011;61:212-236.

2. Cockerell CJ. The pathology of melanoma. Dermatol Clin. 2012;30:445-468.

3. Snels DG, Hille ET, Gruis NA, Bergman W. Risk of cutaneous malignant melanoma in patients with nonfamilial atypical nevi from a pigmented lesions clinic. J Am Acad Dermatol. 1999;40:686-693.

4. Gandini S, Sera F, Cattaruzza MS, Pasquini P, Abeni D, Boyle $\mathrm{P}$, et al. Meta-analysis of risk factors for cutaneous melanoma: I. Common and atypical naevi. Eur J Cancer. 2005;41(1):28-44.

5. Bauer J, Blum A, Strohhacker U, Garbe C. Surveillance of patients at high risk for cutaneous malignant melanoma using digital dermoscopy. Br J Dermatol. 2005;152:87-92.

6. Terushkin V, Dusza SW, Scope A, Argenziano G, Bahadoran P, Cowell $\mathrm{L}$, et al. Changes observed in slow growing melanomas during long-term dermoscopic monitoring. $\mathrm{Br} \mathrm{J}$ Dermatol. 2012;166:1213-1220.

7. Kittler H, Pehamberger H, Wolff K, Binder M. Follow-up of melanocytic skin lesions with digital epiluminescence microscopy: Patterns of modification observed in early melanoma, atypical nevi and common nevi. J Am Acad Dermatol. 2000;43:467-476. 8. Stante M, De Giorgi V, Cappugi P, Giannotti B, Carli P. Noninvasive analysis of melanoma thickness by means of dermoscopy: a retrospective study. Melanoma Res. 2001;11:147-152.

9. Seidenari S, Ferrari C, Borsari S, Benati E, Ponti G, Bassoli $\mathrm{S}$, et al. Reticular grey-blue areas of regression as a dermoscopic marker of melanoma in situ. Br J Dermatol. 2010;163(2):302-309. 10. Bassoli S, Borsari S, Ferrari C, Giusti F, Pellacani G, Ponti G, et al. Grey-blue regression in melanoma in situ - Evaluation on 111 cases. J Skin Cancer. 2011;2011:180980.

11. Salerni G, Teran T, Puig S, Malvehy J, Zalaudek I, Argenziano $\mathrm{G}$, et al. Meta-analysis of digital dermoscopy follow-up of melanocytic skin lesions:a study on behalf of the International Dermoscopy Society. J Eur Acad Dermatol Venereol. 2013;27(7):805-814

12. Fikrle T, Pizinger K, Szakos H, Panznerova P, Divisova B, Pavel S. Digital dermatoscopic follow-up of 1027 melanocytic lesions in 121 patients at risk of malignant melanoma. J Eur Acad Dermatol Venereol. 2013;27(2):180-186.

13. Annessi G, Bono R, Sampogna F, Faraggiana T, Abeni D. Sensitivity, specificity, and diagnostic accuracy of three dermoscopic algorithmic methods in the diagnosis of doubtful melanocytic lesions: the importance of light brown structureless areas in differentiating atypical melanocytic nevi from thin melanomas. J Am Acad Dermatol. 2007;56:759-767.

14. Seidenari S, Ferrari C, Borsari S, Bassoli S, Bassoli S, Cesinaro AM, Giusti F, et al. The dermoscopic variability of pigment network in melanoma in situ. Melanoma Res. 2012;22(2):151157. 